\section{STRESS ANALYSIS AND THE DESIGNER}

A DISCUSSION on "Stress Analysis and the Designer" was opened by Sir Donald Bailey at the Birmingham Conference on April 13 of the Stress Analysis Group of the Institute of Physics. Sir Donald outlined his attitude to stress analysis as an engineering designer. $\mathrm{He}$ needed answers to particular problems which could not be obtained by mathematical methods either because of the complexity of the mathematical solutions or because of design assumptions, unknown boundary conditions or other practical uncertainties. He specified his requirements as the need to measure stresses up to 75-85 tons per sq. in. in steel or 25-30 tons per sq. in. in light alloys, occurring at frequencies from 0 to 25 cycles per second in structural work and up to 50 cycles per second in mechanical work. This required recording apparatus that would respond to at least 1,000 eycles per second. The stresses obtained should be correct to within $2 \frac{1}{2}-5$ per cent for all stresses from 4 tons per sq. in. upwards.

Sir Donald outlined the field conditions under which he required his apparatus to operate. On structural work he found that he had very often to carry out tests in bad weather and on remote sites devoid of a power supply. The structures under investigation were often large and the readings had to be available at a central recording station several hundred feet away from the structure. Experts on strain gauge methods were not usually available, and the equipment used had therefore to be sufficiently reliable to be operated by the practising engineer, who was not generally competent to carry out repairs to electronic equipment if this went out of commission at the crucial moment during a test.

The shortcomings of a number of methods of experimental stress analysis were then discussed. Mechanical and optical strain gauges are generally unsuitable for use in the field because they are incapable of recording localized and dynamic stresses and cannot be adapted for central recording of the readings from a large number of gauges. Sir Donald has found acoustic gauges to be unsatisfactory and too large and heavy for his purposes. Brittle lacquer techniques and photo-elastic methods were mentioned in passing, but neither of these are field methods. The rigid temperature control required for the brittle lacquer methods rules these out for use in the field; photoelastic methods are extremely useful, but necessarily limited to laboratory investigations on small-scale models.

The electric resistance strain gauge is the most widely used method, but Sir Donald Bailey felt that much more development work is needed here; the sticking of the gauges to the structure needs much skill and experience in order to give consistent results. The waterproofing of gauges in the open air has been found difficult. Temperature control and the correct wiring of large numbers of gauges have been found awkward and time-consuming, and the equipment used in the recording of dynamic stresses has not, in general, been found very reliable.

During the discussion which followed, the use of the acoustic strain gauges, particularly those of the Maihak type, was defended; and a number of speakers felt that by virtue of their robustness and freedom from troubles due to changes of temperature, these gauges were eminently suitable for use in static tests of large structures.

A number of speakers felt that the difficulties of mounting electric resistance strain gauges have been exaggerated, but there was general agreement that the waterproofing of gauges in exposed positions is of paramount importance. The general feeling of the meeting was that there is no alternative to soldering the leads to electric resistance strain gauges; plugs and sockets invariably lead to erratic results. Where immediate results are required in the field, the use of pen-and-ink recorders was advocated; a representative of Messrs. Kodak pointed out that immediate results are obtainable from ordinary film and that processing in special solutions in a mobile unit need only take 40 seconds.

There was very general support for Sir Donald Bailey's contention that the manufacturers of electronic devices might pay more attention to the reliability of their products. The point was made that the engineer engaged on stress analysis work should be able to feel the same confidence in his oscillographs, amplifiers and other electrical recording equipment as the average householder has in his domestic wireless set. The view was put forward very strongly that the manufacturers tend to think of their customers too often as experts in electronics, who use the equipment in laboratories where minor repairs can easily be carried out, and do not cater for the engineer who wants to use his electronic gear merely as a tool and who knows no more about the construction of the instruments than is necessary for their efficient use. One industrial research unit was quoted as an example of the waste of effort involved in the present position; in this unit no less than nine members of the staff out of a total of thirty are engaged in the instrument section dealing mostly with breakdowns and troubles caused by insufficient screening of electrical recording instruments. It was made very clear by the discussion that the manufacturers have a long way to go before they achieve a standard of reliability and robustness in their products which will satisfy their customers in the growing field of experimental stress analysis.

E. K. Frankt

\section{INTERNATIONAL INSTITUTE OF WELDING}

$\mathrm{W}$ ELDING has just achieved organisation on an international scale by the formation of the International Institute of Welding, at a meeting in Brussels during June 8-11, attended by the represent. atives of fourteen countries.

At the meeting of the Governing Council on June 11, M. P. Goldschmidt, administrative director of the Belgian Institute of Welding, was elected the first president of the International Institute, and the Council elected as vice-presidents Prof. H. E. Jaeger, lecturer in naval architecture at the University of Delft, and Prof. A. Portevin, president of the French Institute of Welding. One other vice-president is to be nominated by the American Welding Society. M.r. Walter Edström, vice-president of the Swedish Welding Committee, was elected treasurer. A special responsibility has fallen to the British welding com. munity through the election as the first secretarygeneral of the international body of Mr. G. Parsloe, secretary of the British Institute of Welding. 